\title{
Cerebri anatome: Thomas Willis and his circle
}

\begin{abstract}
Studying the structure and function of the nervous system posed enormous problems from ancient times until well after the Renaissance. The central nervous system's anatomy was difficult to fathom because, without fixatives, it rapidly becomes semi-fluid after death. Its function was even more obscure, partly because of the lack of any appropriate investigative method other than observing effects of gross lesions on function, but also, even after anatomy began to be unravelled in the seventeenth century, the prevailing Galenic humoral theories made no predictions that were open to experimental test. However, the new experimental philosophers of the seventeenth century rose to the challenge.
\end{abstract}

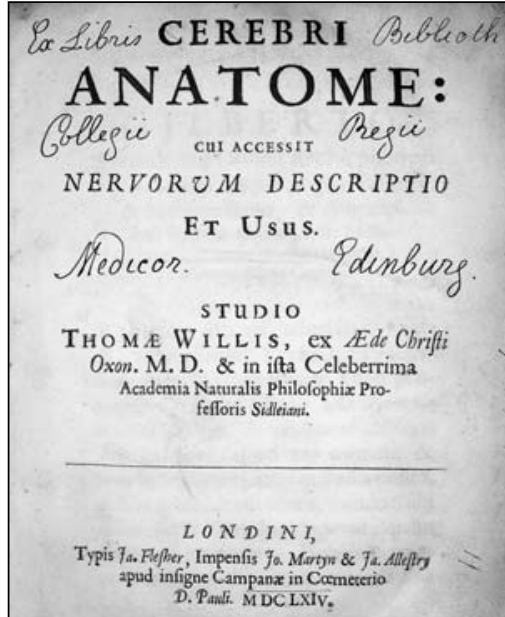

\section{EX LIBRIS RCPE}

Thomas Willis, Cerebri anatome London, 1664
The year 1664 saw the publication of two books that greatly influenced thinking about the nervous system, the Cerebri anatome' of Thomas Willis and the 'original' French version of the Traité de l'homme of René Descartes.

The approach of the two books is very different. Descartes was primarily interested in providing a coherent account of the function of the brain and its relationship to the self. The result was a dualist theory of a machine which functioned on mechanico-hydraulic principles as well as a soul which communicated with, was informed by and ultimately controlled the machine. It is not true that Descartes ignored cerebral anatomy - far from it, in fact - but he was willing to modify his account of the anatomy and even to invent unobserved structures as the theory required. ${ }^{2}$

Willis shared with Descartes the aim of understanding the function of the normal nervous system but also wished to extend this to provide a basis for understanding the pathology of the diseased brain. He believed - or at least hoped - that meticulous examination of the details of the anatomy of the human nervous system and comparison of this with animal neuroanatomy would provide such a basis. For him, observation of real structure was paramount and was not to be subject to modification or invention to fit any theory. Willis was truly an experimental philosopher in the tradition of William Harvey; for both men 'ocular demonstration' was absolutely paramount and not authority, received opinion or speculation.

An excellent and still eminently readable English translation of a number of Willis's works, including
Cerebri anatome, by the poet, playwright and translator Samuel Pordage, was published in $1681 .^{3}$ All the English quotations below are from this translation, of which the Sibbald Library has a copy.

In his preface, Willis sets out his intentions thus:

Wherefore all delay being laid aside, I determined with my self seriously to enter presently upon a new course, and to rely on this one thing, not to pin my faith on the received Opinions of others, nor on the suspicions and guesses of my own mind, but for the future to believe Nature and ocular demonstrations:* Therefore thenceforward I betook myself wholly to the study of Anatomy: and as I did chiefly inquire into the offices and uses of the Brain and its nervous Appendix, I addicted myself to the opening of Heads especially, and of every kind [that is, of many species] ... and so a firm and stable Basis might be laid, on which not only a more certain Physiologie than I had gained in the Schools, but what I had long thought upon, the Pathologie of the Brain and nervous stock, might be built.

Although Willis is now best known as the first to describe accurately the details of the circular arterial anastomosis at the base of the brain that bears his name, Cerebri anatome was also a much more accurate description of the anatomy of the brain and cranial nerves than had previously been given. It is the first comprehensive and satisfactory account of the gross anatomy of the human nervous system. Willis was part of the circle of experimental philosophers in Oxford in the 1660s and was assisted in his observations and interpretation by others of the group, particularly by Richard Lower (|63|-9|) who would, five years later, publish his own great work on the circulation. Willis is generous in his acknowledgment of a great debt to the skill of Lower's dissection; indeed, his generous acknowledgements make it clear that although Willis was the driving and coordinating force, Cerebri anatome is the result of close collaboration:

And here I made of the Labours of the most Learned Physician and highly skilful Anatomist, Doctor Richard Lower, for my help and Companion; the edge of whose Knife and Wit I willingly acknowledge to have been an help to me for the better searching out both the frame and offices of before hidden Bodies... 


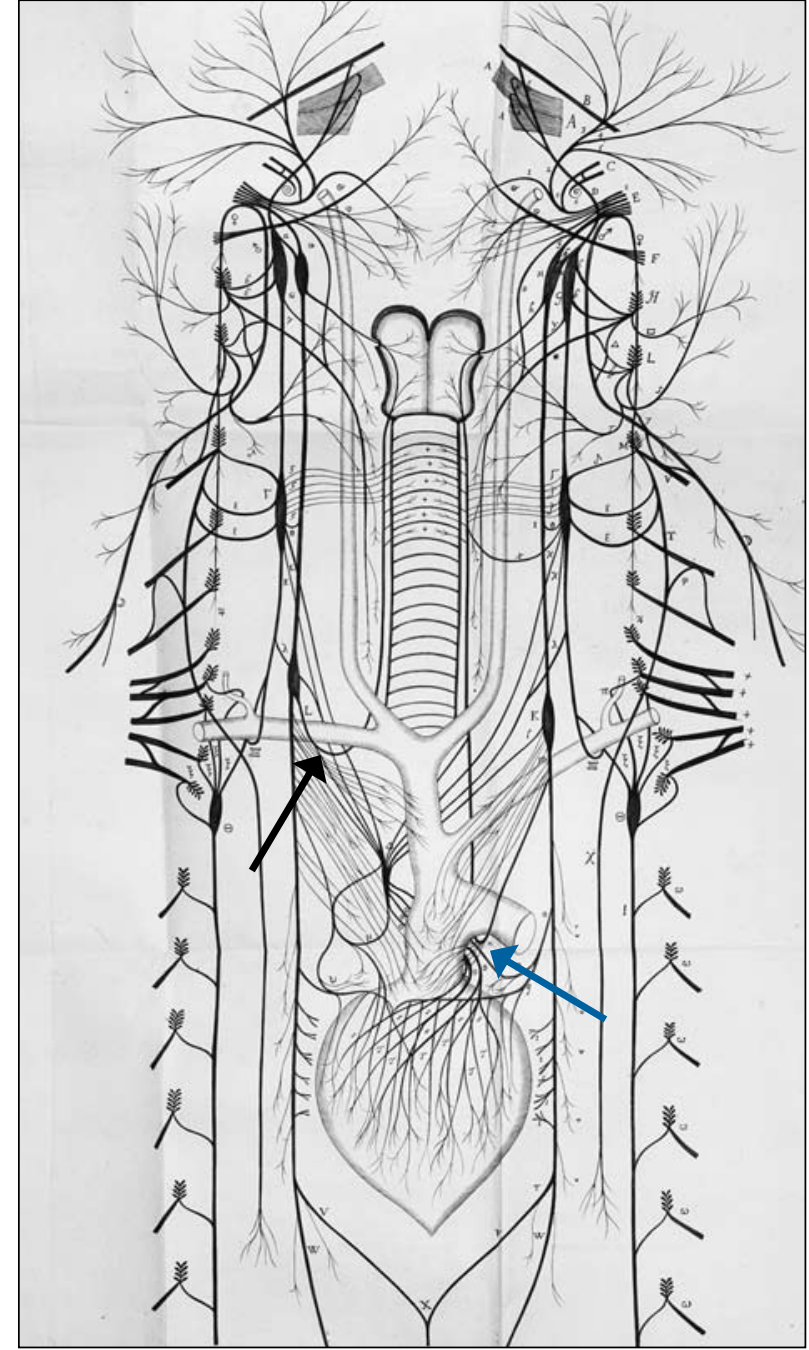

FIGURE I Diagram of the distribution of some of the cranial and spinal nerves and of the 'wandering pair' (vagi), the accessory and phrenic nerves. Note the recurrent laryngeal nerves shown, correctly, looping round the subclavian artery on the right (black arrow) and the aortic arch on the left (blue arrow) and giving off cardiac branches.

After this when we entred upon a far more difficult task viz. the Anatomy of the Nerves [Figure I] then very much appeared the plainly to be admired skill of this Man, as also his indefatigable Industry, and unwearied Labour: For having prosecuted with a most exact search, all the divarications, wandering on every side of the Nerve, how minute or small so ever, and immersed, and variously infolded within other Bodies, and so turning over the Labyrinths of the Branches, and shoots of every pair, far and near diffused, he drew out with his own hand the Schemes, Images or Draughts of them and also of many passages of the Blood, as they appear in this Tract; which indeed, that they might be faithfully and most exactly shewn, without any falsity or errour, he caused, that no Table might contain scarce any line or the most light passage, whose confirmation and exact habitude he had not found proved by the marks or inspection of many Animals for that purpose killed.

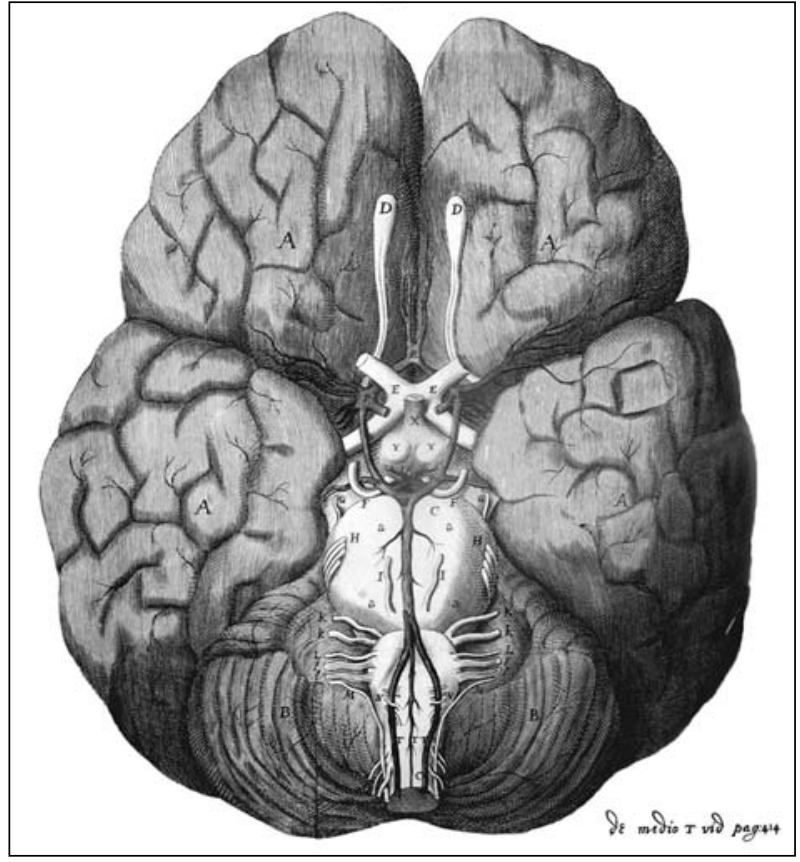

FIGURE 2 Wren's figure of the base of the human brain, showing the arterial anastomosis, now called the Circle of Willis, and a number of the cranial nerves.

Another collaborator was the physician (Sir) Thomas Millington (1628-1704) who was a close friend of Willis and succeeded him as Sedelian Professor of Natural History in 1675. He later developed a lucrative London practice, and was very active in the Royal College of Physicians of London, becoming its president from 1696 until his death.

The third principal collaborator was Christopher Wren, recently (166I) appointed Savilian Professor of Astronomy; he took part in the dissections and in the discussions, but his most striking contribution to the work was to draw many of the illustrations for Cerebri anatome (Figure 2). His architectural renown was yet to come.

But the other most renowned Man, Dr. Wren, was pleased out of his singular humanity, wherewith he abounds, to delineate with his own most skilful hands many Figures of the Brain and Skull, whereby the work might be more exact.

Willis was under no illusions about the difficulty of understanding the function of the nervous system; he is explicit about why this was so much more difficult than understanding the functions of other organs:

For in most of the Viscera and Vessels, the Contents and contained humors, as also their passages within the larger Cavities of the containing parts, are discerned by the sight: But in the Brain and Nerves, neither the rushings on or impressions, viz. the Animal Spirits themselves, nor their traits or footsteps, can any ways be seen. Wherefore to 
explicate the uses of the Brain, seems as difficult a task as to paint the Soul, of which it is commonly said, That it understands all things but it self; for in truth, the unwearied labour of the Brain beholds or searches the hidden places of other Bodies, in the mean time the oeconomy or regiment of its own Family and Kingdom being wholly hid and unknown.

Here one may imagine Willis thinking wistfully of William Harvey's success in understanding the action of the heart as the result of his observations and experiments. Willis had been a student in Oxford about the time that Harvey was briefly Warden of Merton College, early in the Civil War, although Harvey left Oxford in late 1646, the year that Willis obtained his medical degree.

Willis was a man notable for his religious observance in difficult times. Anglican services were held in secret at his home during the occupation of Oxford by the Parliamentarian army. He makes it quite explicit in the dedication of Cerebri anatome to the Archbishop of Canterbury that natural philosophy and Christian theology are not to be seen as alternatives nor as competitive. But, unlike Descartes, he does not speculate on the relationship of the soul to the body. His more modest aspiration is:

But what we profess to be performed by us in the following Tract, and hope for the future from the help or labour of others, is chiefly this; to wit, that we have not rashly described the parts themselves, of which the Anatomy is instituted, but that we have

\section{REFERENCES}

I Willis T. Cerebri anatome, cui accessit nervorum descriptio et usus. London: James Flesher, Joseph Martyn and James Allestry; I664.

2 Donaldson IML. The Treatise of man (De homine) by René Descartes.J R Coll Physicians Edinb 2009; 39:375-6.

3 Willis T. The remaining medical works of that famous and renowned physician Dr Thomas Willis. Transl. S Pordage. London: Dring, Harper, Leigh and Martyn; 168I.

4 Symonds C. Thomas Willis, F.R.S. (162I-1675). Notes Rec R Soc Lond 1960; I5:91-7. doi:10.1098/rsnr.1960.0008 with diligent care and great trust collected the various appearances and Arguments of Observations by a manifold Dissection.

This he and his friends achieved magnificently. Cerebri anatome was a new departure in its precision and thoroughness. The evidence of Lower's meticulous skill in the dissection of the peripheral nervous system leaps from the fine engravings. The results of the endeavours of Willis's circle do truly form the base from which the gross anatomy of the brain and spinal nervous system could be, and was, built.

Willis made other important contributions to medicine and pathology. He realised that the circular anastomosis that now bears his name would provide an alternative route for the cerebral blood supply if one carotid were to be obstructed. He distinguished between local and generalised epileptic attacks and proposed that epilepsy was caused by a sort of explosion of nervous activity. $\mathrm{He}$ described a type of palsy in which the degree of weakness varied with time and was made worse by fatigue - the disorder that we now recognise as myasthenia gravis.

For a brief account of Willis's life and more information about the seventeenth-century physician and experimental anatomist, including more about his observations on the cerebral arteries and the subjects of his other publications, the reader is referred to Symonds. ${ }^{4}$

\section{IML Donaldson, Honorary Librarian, RCPE} (email: i.m.I.d@ed.ac.uk)

\section{NOTE}

* 'Ocular demonstration': Willis's Latin is sed in posterum ex Naturae

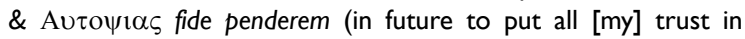
Nature and in my own observations). The 168I translation's use of 'ocular demonstration', although it fits very well the idiom of the time, is a little misleading for the modern reader. William Harvey's famous phrase on 'ocular demonstration' in the dedicatory letter to Dr Argent of the De motu cordis was: Sed iam per novem \& amplius annos multis ocularibus demonstrationibus in conspecto vestro confirmatam (For nine years and more now, I have shown the correctness [of my discovery] by visible demonstrations before your eyes). Harvey says that he has shown his results to others for them to observe and verify. Willis speaks of uncovering

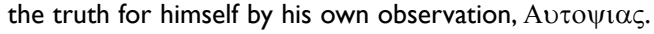

